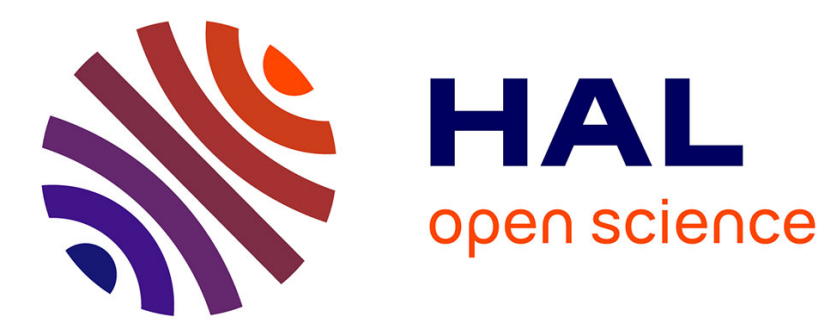

\title{
Moving towards a 5D cardiac model
}

\author{
Houneida Sakly1, Ramzi Mahmoudi, Mohamed Akil, Mourad Saïd, Moncef \\ Tagina
}

\section{To cite this version:}

Houneida Sakly1, Ramzi Mahmoudi, Mohamed Akil, Mourad Saïd, Moncef Tagina. Moving towards a 5D cardiac model. Journal of Flow Visualization and Image Processing, 2019, volume 26, p. 19-48. 10.1615/JFlowVisImageProc.2018027194 . hal-02181106

\section{HAL Id: hal-02181106 https://hal.science/hal-02181106}

Submitted on 11 Jul 2019

HAL is a multi-disciplinary open access archive for the deposit and dissemination of scientific research documents, whether they are published or not. The documents may come from teaching and research institutions in France or abroad, or from public or private research centers.
L'archive ouverte pluridisciplinaire HAL, est destinée au dépôt et à la diffusion de documents scientifiques de niveau recherche, publiés ou non, émanant des établissements d'enseignement et de recherche français ou étrangers, des laboratoires publics ou privés. 


\title{
Moving towards a 5D cardiac model
}

\author{
Houneida Sakly ${ }^{1}$, Ramzi Mahmoudi ${ }^{2}$, Mohamed Akil ${ }^{2}$, Mourad Said ${ }^{3}$, Moncef Tagina ${ }^{1}$ \\ ${ }^{1}$ COSMOS Laboratory -National Institute of Computer Sciences - Campus University of Mannouba - \\ Tunisia
}

${ }^{2}$ L'IGM, CNRS-UMLV-ESIEE UMR8049 mixed unit, University Paris-Est

Descartes city, BP99, 93162 Noisy Le Grand, France
${ }^{3}$ Radiology and Medical Imaging Unit, International Center Carthage Medical, Tourist Area "JINEN EL OUEST"-5000 Monastir, Tunisia.

\{houneida.sakly,ramzi.mahmoudi,mohamed.Akil\}@esiee.fr, mouradsaid@yahoo.fr, moncef.tagina@ensi-uma.tn

\begin{abstract}
The medical diagnosis process requires several steps to identify the types of cardiac pathologies. The segmentation step is used to determine the measurements for cardiac abnormalities on the short axis of the 4D acquired in MRI, but this phase remains limited on the blood flow sequences. The MRI modality allow to the experts to quantify the stenosis and the regurgitation of aortic blood flow. The parameters extracted from the flow sequences, after segmentation, make it possible to identify the valvular pathologies, but they are not sufficient to complete the medical prognosis as well as the lack of precision of these measurements. In this paper, we propose to make a coupling between the 4D cardiac cuts with their study of blood flow through the technique of registration and reconstruction. The interest of the purpose of the blood flow as fifth dimension is to improve the accuracy of the cardiac parameters and the extracting of measurements for valvulopathies in the process of assistance to the decision for the experts An example was introduced in this context through the development of cloud services for patient-specific simulations of blood flows through aortic valves as well as an OsiriX software for 5D visualization that combines a 4D sequence and the functional flow dimension. In this framework, we proposed a processing chain to lead towards a 5D solution. Another problem is raised is the choice of the appropriate architecture to solve the problem of hybrid parallelization for the processing of these cardiac images. To test the constraints of time of the concept of 5D, we need a GPU graphics processor acquired in MRI, as well as a CPU processor to perform the complexity of calculation and the operations applied to the algorithms of image processing.
\end{abstract}

Index Terms - Cardiac pathologies, MRI, blood flow sequences, segmentation, coupling, fifth dimension, hybrid parallelization, CPU, GPU, complexity of calculation.

\section{INTRODUCTION}

Cardiovascular diseases are considered among the leading causes of death in low and middle-income countries. Among the behavioral risk factors that can cause these diseases we mention: high levels of nicotine in the blood, nutrition upheaval, overweight, physical inactivity and alcoholic addiction. According to the last statistics in the World Health Organization report [1], 49\% of the Tunisian population dies from heart diseases in 2014. The need for a reliable and relevant diagnosis for heart diseases leads to a multiple choice of modalities as through the echocardiography, cardiac CT and MRI that can benefit from the wide variety of medical imaging systems. MRI Cardiac is strongly preferred over the other modalities because it provides an anatomical vision of the heart and gives the structure of the cardiac function. The MRI seems to be the most suitable modality for the study of the cardiopathies and valvular pathologies as it is considered very efficient to quantify the severity of valvular stenosis as well as the quantification of regurgitations. The development of tools for the treatment of cardiac sequences based on the MRI features is used to ensure an optimal extraction of parameters describing the morphology and the heart's function. In this context, we speak of a multimodal or hybrid imaging that combines an anatomical and 
a functional vision. The structural aspect has been clarified through the description of the shapes and structures of a living organ, while the functional aspect is occurred through the functional examination of organs by specifying the alteration of physiological functions in organs that are affected by a disease. The phenomenon of metabolism depends on the extraction of a multimodal information that includes the functional information and structural one [2].

In fact, research in this area focuses on improving the spatial resolution, the temporal criterion and the chosen sensitivity of the methods of simulation and estimation[3], [4]. We put forward in this case two methods: the estimation and simulation methods [5]. In particular, estimators exploit the knowledge obtained a priori by using a measure of motion (propulsion of blood / cardiac flow). To detect their movement, simulators predict each movement with a single initial state. The dependence of estimation methods has greatly reduced their interest. Furthermore, even though their average precision that is appreciable varies between 3 to $4.5 \mathrm{~mm}$ according to the used methods. They do not reduce the patient's dose (injection of contrast product) due to imaging tests. In the opposite side, simulation methods offer substantially similar information but usually they take a long response time [6]. In this context, we have chosen to use estimation methods to evaluate the accuracy of cardiac measurements as well as measurements for valvular abnormalities. Our contribution in this paper is reflected via the proposition of a processing chain to lead towards a 5D solution model $(4 \mathrm{D}+$ functional dimension of the blood flow) in view of the difficulties encountered by the expert during the medical interpretation.

This paper presents a mathematical comparison between the lung and the cardiac model 5D, a study of the characteristics of some existing software for the processing of the blood flow. We also presume the medical problem and our proposal to solve it as well as the suitable architecture to implement the solution.

The rest of this paper is organized as follows: Section 2 presents the related works to show the impact of the flow study in the medical diagnosis. Section 3 introduces the medical context, the interest of choosing the MRI modality, some characteristics for existing software and their limitations for the study of the blood flow. Section 4 explains the medical issue, section 5 presents the solution proposed and the challenges, section 6 we mention a comparison between the lung and the cardiac model 5D, section 7 to propose the appropriate architecture to implement the processing chain in section 5 .

\section{II.STATE OF ART FOR THE STUDY OF BOOD FLOW}

This part is dedicated to present works that focus on the analysis of flow sequences for cardiac images with MRI used to give a prognosis and diagnostic interpretation. In fact, we shed light on the deep terms that revolve around this context. The medical diagnostic phase requires fundamental basis techniques for the processing of medical images. Thereafter, we mention an oversight about the recent quest concerning the impact of $4 \mathrm{D}$ blood flow processing on medical diagnosis.

Cardiovascular magnetic resonance (CMR) is a non-invasive cardiac imaging modality that can perform a multiparameter evaluation of the heart and blood vessels, including the structure, function, tissue characterization, perfusion, circulation and the metabolism. The fundamental principles of the CMR are to develop some techniques that contain fast data acquisition with perfusion sequences and tissue characterization methods. In the evaluation of innovative quantitative techniques such as $4 \mathrm{D}$ flow imaging and the great vessels, the CMR can assess to cardiac metabolism [7]. The MRI phase contrast was used in a conventional routine in the MRI cardiac to accurately 
determine the measure of the dynamic flow [8] . However, a recent volumetric optimization, time-resolved 3D and 4D Flow, led to the suppression of the dynamic flow visualization modes and quantified the abnormal hemodynamics which are associated with. They focus on the emerging applications of 4D flow to the cardiac output by marking the aortic disease. A deep study was developed for the imaging protocol to simultaneously measure the flow in the circle of Willis, the carotid and the vertebral arteries during the increase in $\mathrm{CO} 2$ [9]. The 4D MRI flow methods are sufficiently sensitive to detect non-uniform changes and cross-sectional rates in $\mathrm{CO} 2$. The 4D flow is a non-invasive and a reliable tool providing a spatial and temporal resolution in the clinically achievable scan time without a contrast agent. This approach can be used to query the regional control stroke in health and disease. A comparison in the pre-treatment workflow for the conventional workflow was analyzed the abdominal hemodynamics in patients with hypertension using noise filters for 4D data with MRI [10]. In fact , the 4D Flow with MRI is used for analyzing the attitude of vortices and transvalvular pressure gradients in patients with a valvular prosthesis compared to healthy volunteers and age-appropriate [11]. The results show that for a pulsatile stenotic flow allows visualizing, using a 4D MRI, a jet-shaped plug. This jet distinguishes between two regions: the local fastest flow region that occurred to the post-systole phase in the post-stenotic region, and the region of a typical flow of stenotic fluid to the systole phase [12] . The use of 4D flow quantification can lead to valid conclusions in comparative studies that use similar image resolution for the diagnosis of congenital heart disease [13]. Moreover, the blood flow is used to rise the characteristics of the ascending of aortic flow, which are influenced by the aortic valve replacement. These data indicate the potential of 4D-flow MRI to obtain new ideas for medical interpretation on the behavior of the aortic[14]. In this context, the blood flow allows evaluating the severity of the aortic stenosis using the 4D flow jet for the measurement of the effective orifice area. The integration of the flux image in the medical diagnostic phase becomes a necessary step for a complete diagnosis in the cardiac MRI exam [15].

It is concluded that the purpose of these studies is to evaluate and implement the importance of flow sequences for a medical diagnosis [16]. The objective of this study is not to manifest a comparison between approaches for the study of flux but to show the limited view of the morphological structure and the lack of some measurements such as velocity for the study of blood flow in cardiac images. In fact, most of this work does not manipulate the segmentation phase for flow sequences view the difficulty of the localization of the area of interest, but on the other hand, the phenomenon of fluid interaction manifests the flow path the field of displacement in the vessels and its behavior [17]. Several research works in the literature presented in [18] [19] [20] [21] [22] [23] [24]have focused on the intensive use of blood flow for the identification of stenosis based on very precise measurements (dynamic pressure, vortex field, number of Reynolds, wall shear stress ...). Our medical context is turn around on the use of CFD modules for detecting regurgitation syndromes. Various works highlight this concept to present an approach to decision support [25] [26] [27] [28] [29] .

In this section, we have cited some works that emphasize the interest of some techniques in the studying of flow to identify some pathologies in a well-defined medical context [30]. The flow interpretation offers the expert more medical information about the valves and the aorta, parameters and measures that are in relief with the notion of flow which collaborates to make the right decision and deduce an undoubted conclusion of the examination with 
a minimum rate of error [13]. In what follows, our goal is to highlight 4D imaging with the study of the blood flow for a medical prognosis and the feat of this notion in the concept 5D.

\section{MEDICAL CONTEXT AND EXISTING SOFTWARE FOR THE PROCESSING OF BLOOD} FLOW

\section{A. Interest of cardiac MRI}

Anatomical MRI sequences have raised developments in terms of the particular image analysis to estimate global parameters of the heart as cavity volumes, ejection fraction and regional settings as segmental parietal thickening. In addition, MRI is recognized as a reproducible and non-invasive technology [2]. Left ventricular dysfunction today is a public health problem, as this disease increases steadily. The improved decision in the acute phase of infarction, the increasing number of obese people, improving the management of hypertension and the aging of the population makes us think that this condition will continue in the future. The role of cross-sectional imaging is central in the assessment and monitoring of patients taking a prominent place because of the indisputable advantages of cardiac MRI (tissue characterization and analysis of the function of the left ventricle) compared to other conventional methods[31]. We propose a comparative study between the MRI and other conventional modalities in table 1 .

\begin{tabular}{|c|c|c|c|c|}
\hline Modality & Measurable function & $\begin{array}{c}\text { Spatial } \\
\text { resolution }\end{array}$ & $\begin{array}{l}\text { Temporal } \\
\text { resolution }\end{array}$ & Limits \\
\hline TEP & $\begin{array}{l}\text {-Metabolism } \\
\text {-Perfusion }\end{array}$ & $\begin{array}{l}-4 \mathrm{~mm} \text { typical } \\
-2.1 \mathrm{~mm} \text { for best } \\
\text { resolution of } \\
\text { camera }\end{array}$ & - $40 \mathrm{~ms}$ (20 phases) & $\begin{array}{l}\text {-Consequently -Equipment } \\
\text {-Need cyclotron } \\
\text {-Space -Resolution }\end{array}$ \\
\hline TEMP & $\begin{array}{l}\text {-Perfusion } \\
\text { - Function } \mathrm{G}\end{array}$ & $-8 \mathrm{~mm}$ & $\begin{array}{l}\text { - Synchronization } \\
\text { ECG }\end{array}$ & $\begin{array}{l}\text { - Spatial resolution } \\
\text {-Injection Of a contrast product }\end{array}$ \\
\hline Angiocardiography & - Function G & $\begin{array}{l}-<1 \mathrm{~mm} \\
-2 \mathrm{D} \text { multi-plans }\end{array}$ & $-20 \mathrm{~ms}$ & $\begin{array}{l}\text {-Injection of a contrast product } \\
\text { - Project of imaging }\end{array}$ \\
\hline CT SCAN & $\begin{array}{l}\text {-Perfusion } \\
\text { - Anatomy (heart, } \\
\text { vessels) }\end{array}$ & $-3 \mathrm{D}, 600 \mu \mathrm{m}$ & $-100 \mathrm{~ms}$ & $\begin{array}{l}\text {-Injection Of a contrast product } \\
\text {-Resolution time still limited }\end{array}$ \\
\hline MRI & $\begin{array}{l}\text { - Perfusion } \\
\text { - Shapes, Volume }\end{array}$ & $\begin{array}{l}-3 \mathrm{D}, \sim 1 \mathrm{~mm} \\
-2 \mathrm{D}+, \sim 1 / 7 \mathrm{~mm}- \\
2 \mathrm{D}+, 2-3 \mathrm{~mm} \\
500 \mu \mathrm{m} \text { for } \\
\mu \mathrm{MRI}\end{array}$ & $\begin{array}{l}\sim 15 \mathrm{~ms}, \\
- \text {-Synchro ECG } \\
\text {-Free respiration }\end{array}$ & $\begin{array}{l}\text { - contradiction } \\
\text {-Request Specific MRI for } \\
\text { patients holders of PM } \\
\text { (Pacemaker) }\end{array}$ \\
\hline Echocardiography & - Ventricular Function & $-1.5 \mathrm{~mm}$ & - 30-40 images/sec & $\begin{array}{l}\text { - Problem of Image sharpness --- } \\
\text { When in doubt on discussion, } \\
\text { consideration must be repeated in } \\
\text { full, ideally by another expert }\end{array}$ \\
\hline ECG [5] & -Electro diagram & $-5 \mathrm{~cm}$ & -A few ms & $\begin{array}{l}\text { Very affected by bone tissue } \\
\text { - Response broadcasts } \\
\text { - Requires a reference }\end{array}$ \\
\hline $\mathrm{MCG}[5]$ & $\begin{array}{l}\text { - Muscle contraction } \\
\text {-Cardiac cycle }\end{array}$ & $-<1 \mathrm{~cm}$ & $-A$ few ms & $\begin{array}{l}\text { - Cost } \\
\text { - Dimensions } \\
\text { - Weight }\end{array}$ \\
\hline Multi-slice scanner & -Cardiac Cycle & $-0,35 \mathrm{~mm}$ & $\begin{array}{l}\text {-Synchronization } \\
\text { with ECG } \\
-200-250 \mathrm{~ms}\end{array}$ & $\begin{array}{l}\text {-Fragmentation Of anatomical } \\
\text { continuity } \\
\text { - Isolated foison details } \\
\text {-Poor Visualization of complex } \\
\text { 3D structures } \\
\text {-Problems in communication } \\
\text { with the } \\
\text { related slices }\end{array}$ \\
\hline
\end{tabular}


In comparison with the other modalities mentioned in the table, the contribution of MRI is reflected in its interesting characteristics. The MRI has the best resolution time $=15 \mathrm{~ms}$, as well as this modality, accepts 3D and $4 \mathrm{D}$ formats with a spatial resolution $=1 \mathrm{~mm}$. Doppler echocardiography is usually very effective in quantifying the severity of valvular stenosis. However, it is limited in the quantification of regurgitation or color Doppler evaluation is semi-quantitative and can be induced by technical or hemodynamic factors [2].

\section{B. Flow sequences and valves}

The quantitative measurement of magnetic flow resonance using velocity-sensitive sequences (SSV) has been used since the 1980s and has witnessed a renewed interest in recent years. Since then they became of powerful gradients and the reduction of acquisition time, that follows it, allows to add an essential functional information to any morphological MRI cardiac imagery. The SSV allows an accurate estimation of the velocity profiles through a valve or vascular structure for a more accurate quantification of flow and valve disease. MRI is not limited by the problems of acoustic penetrations and allows a better visualization of the morphology and valvular flow in the cardiovascular structures. The valvular diagnostic strategy provides an almost complete information to plan treatment options. Furthermore, it is the only reliable technique which helps provide morphological information such as the number of valve leaflets and valvular thickening [2]. We note that among the factors on which it depends, is the process of acquiring cardiac images: The spatial resolution and contrast, artifacts, and noise and the resolution time. To ensure the best image quality possible, and to detect any malfunction, regular quality control is recommended. Concerning the MRI control, we identify a set of different parameters like the signal, the geometric parameters (Linear and affine transformation, the angles of rotation), artifacts and spectroscopy. We mentioned the highlighting of the causes, which influence the quality of cardiac images with the imaging concept of flows; we present the main characteristics of these factors in table 2 [32]:

\begin{tabular}{|c|c|c|c|}
\hline $\begin{array}{l}\text { comparison } \\
\text { between }\end{array}$ & Spatial resolution & Temporal resolution & Noise and artifacts \\
\hline characteristics & $\begin{aligned} & \checkmark \text { Is the sharpness } \\
& \text { of the image } \\
& \checkmark \text { Characterized by } \\
& \text { the voxel volume } \\
& \checkmark \quad \text { The precise } \\
& \text { quantification of } \\
& \text { flow requires: } \\
& \text { Sufficient spatial } \\
& \text { resolution to accurately } \\
& \text { measure the vessel } \\
& \text { diameter }\end{aligned}$ & $\begin{array}{ll}\checkmark & \text { Number of images } \\
& \text { acquired per second } \\
\checkmark & \text { The precise } \\
\text { quantification of flow } \\
\text { requires: a precise } \\
\text { time resolution and } \\
\text { covering the entire } \\
\text { cardiac cycle }\end{array}$ & $\begin{array}{l}\checkmark \text { The report signal / } \\
\text { noise ratio (SNR) } \\
\text { depends on: } \\
\text { Stable factors stable: field } \\
\text { intensity, wave sequence, } \\
\text { tissue characteristics } \\
\checkmark \quad \text { sequence } \\
\text { parameters: voxel } \\
\text { size (spatial } \\
\text { resolution), } \\
\text { number of } \\
\text { excitations, } \\
\text { receiver bandwidth }\end{array}$ \\
\hline
\end{tabular}

Table 2.Table 2: Acquisition process characteristics of cardiac MRI

The interest of the study of flows is introduced into four main areas: pulmonary artery zone, aorta area, the area containing the atrium and right ventricle, an area containing the atrium and the left ventricle, as well as congenital heart disease. Among the most common congenital cardiac defects, we mention interventricular communication, interauricular communication, the transposition of large vessels. The interauricular communication (AIC) results in a communication between both right and left auricles of the heart resulting from a defect in their common wall 
namely the interatrial septum. The interventricular communication (VIC) is the persistence of a hole in the interventricular septum that separates the two ventricles. The transposition of the great vessels (TGV) is defined by an inversion (transposition) of the large vessels emerging from the ventricles, the pulmonary artery and the aorta. The necessity of a surgical operation involves a study of blood flow before and after this intervention[32].

C.Existing software's for the processing of blood flow

MRI is one of the modalities that acquires flow sequences, the expert must have a software able to read this format so that these types of images will be legible and interpreted. In this section, we have studied some characteristics of some existing software that makes the processing of the blood flow faithfully as well as their limits. In this context, we have chosen to cite some clinical solutions that helps the experts to interpret the blood flow. In fact, the notion of cardiac flow interpretation and medical prognosis of valvulopathies is passed through the segmentation step in the hunting chamber and correlating between the valve position in this section and in the heart flow sequence.

It was being noticed that experts use ReportCARD as a decision-making tool for segmentation in the Radiology and Medical Imaging Unit in the International Center Carthage Medical which created by General Electric Healthcare. Unfortunately, it has not been updated since 2008. The automated Left Ventricular (LV) segmentation with the clinical tool "ReportCARD" allows for the quantification of the left ventricular volumetric parameters with a minimal user input from the user. The automated segmentation can improve the accuracy of quantifying and reporting key LV volumetric parameters like LV ejection fraction, and LV stroke volume. It also has only four parameters (Flow, Pixel wise Velocity, Peak and Absolute Envelope). This tool cannot offer several parameters to help experts make the right decision in the study of the cardiac flow. In this case, the prognosis is becoming very doubtful for the valvulopathies.

QFlow [33] is the Medis software solution for the quantitative analysis of velocity-encoded MR studies founded by Medis medical imaging systems for more than 25 years. It enables cardiologists, radiologists, and technicians to quantify arterial and transvalvular blood flow. QFlow is characterized by an automatic contour detection, easyto-use functionality for editing contours, flow analyses of vessels, flow analyses of valves, and flow analyses of cerebral spinal fluid. Fig. 1 shows the interface of this software which makes it possible to make the matching between the hunting chamber and the flow sequence. This software makes analyses for the flow volume and the means of velocity to quantify two cases of valvular pathologies: stenosis and regurgitation.

We note that a volume of flow, as well as a fraction of regurgitation and the quantification of the average velocity flow, are calculated. Despite this software demonstrates an automatic calculation of flow volumes, velocities, and the fraction of regurgitation, measurement of slow flow volumes and velocities, but these parameters remain insufficient for both cases of these valvular pathologies.

Another software called CAAS MR Flow [34] founded by Esaote biomedical equipment which makes 4D flow processing. CAAS MR 4D Flow is specifically designed to extract relevant information from 3D phase contrast MR images. Automatic 3D segmentation of the data provides interactive visualization of flow patterns by means of streamlines, time-resolved path lines and color-coded vectors. 


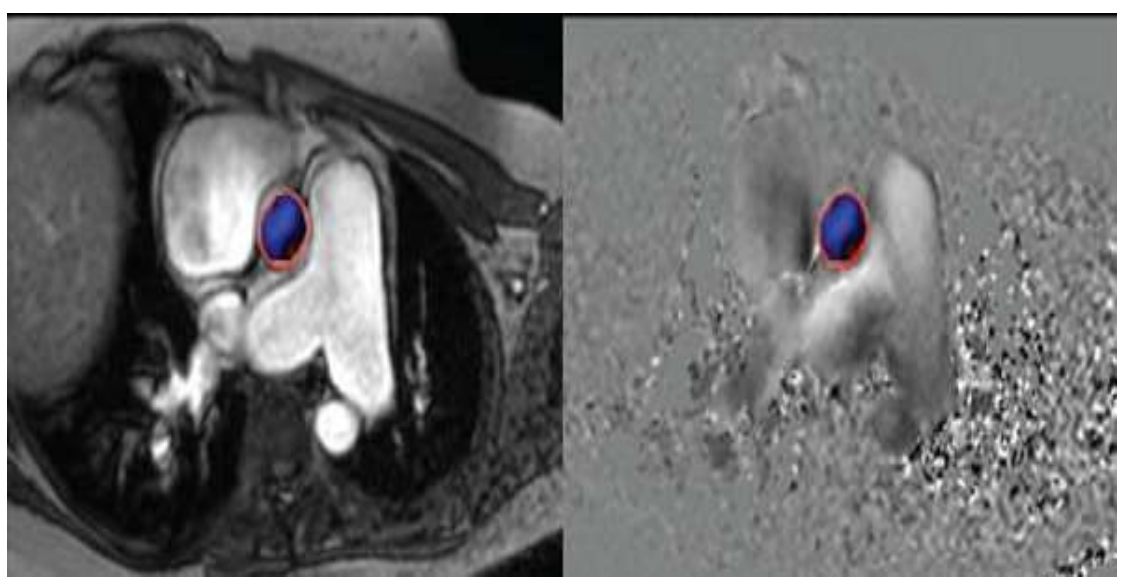

Figure 1. Matching between a flow sequence and the cut of hunting chamber $4 D$

This software provides a comparison between two steps of segmentation in the different planes in the aorta and offers different sets of data by 2D flow parameters in Fig.1. A quantification of flow velocity will be the basis for a medical interpretation for valvulopathies. These types of software remain to complain of the lack of accuracy of these parameters (volume of the ejected flow, volume of the regurgitated flow, regurgitation fraction (ejected flow / regurgitated flow), ejection volume (ejected flow - regurgitated flow.)) and the inadequacy of these measures for cases of valvular stenosis. This may influence the medical conclusion of the cardiac examination for patients that have valvular narrowing.

To avoid the problem of matching between a flow sequence and 3D or 4D image, which can cause errors when calculating parameters (regurgitation, stenosis) of valvular diseases, Osirix proposed a $5 \mathrm{D}$ viewer to solve the issue of segmentation in a flow sequence and in a 4D cardiac sequence which may lead to the calculation of not accurate measures.

Osirix software [35] is an image processing software dedicated to DICOM images produced by a medical imaging equipment (MRI, CT scanners, ultrasound equipment and more). It is compatible with the standard format DICOM. Through the communication protocol, Osirix is able to transfer and receive operations from PACS.This software is designed to create the $5 \mathrm{D}$ visualization of the multimodal and multidimensional data: viewer $2 \mathrm{D}, 3 \mathrm{D}$ visualization which allows to realize a rendered volume and surface as well as a multiplanar reconstruction (MPR) and the maximum projection intensity (MIP), 4D viewer by adding the temporal dimension, and the 5D viewer by offering the functional dimension. OsiriX is the world's most advanced, and open source medical image viewer that competes directly with industry-leading platforms. Unfortunately, OsiriX has not been commercialized yet. Consequently, we present the design of this software and exploiting these opportunities to open a new research axis in $5 \mathrm{D}$ format.

In this section, we presented the segmentation tool in clinical routine as well as a comparative study between two existing software which is in relief with the blood flow sequences and their limitations. A deep analysis of the development of cloud services or patient-specific simulations of blood flows through aortic valves based on ANSYS Fluent was mention in [36]. In this context, we can mention several works that use CFD modules with Fluent for the detection of aortic stenosis with MRI as well as the extraction of several parameters for the medical prognosis [37] [38] [39] [40] [41]. 
OsiriX solves the problem of matching between a 4D flow of hunting chamber and the absence of detailed parameters to make a complete diagnosis for and valvular abnormalities. At the end of this section, we summarize the main features of the above-mentioned software as well as a synthesis of quantization of stenosis, valvular leakage and 5D modeling in table.3:

\begin{tabular}{|l|c|c|c|}
\hline software & \multicolumn{3}{|c|}{ comparison criterion } \\
\hline QFlow & Stenosis quantification & $\begin{array}{l}\text { Regurgitation } \\
\text { quantification }\end{array}$ & 5D Model \\
\hline $\begin{array}{l}\text { Caas MR Flow (Pie } \\
\text { medical imaging } \\
\text { Solution) }\end{array}$ & $\checkmark$ & $\checkmark$ & Not supported \\
\hline Fluent (CFD modules) & $\begin{array}{l}\text { it can be deduced via } \\
\text { the extraction of the } \\
\text { parameters (Reynolds } \\
\text { number, pressure, } \\
\text { vorticity ...) }\end{array}$ & $\begin{array}{l}\text { it can be deduced via } \\
\text { the extraction of the } \\
\text { parameters (the ratio } \\
\text { between the outgoing } \\
\text { and the incoming } \\
\text { flow) }\end{array}$ & Not supprted \\
\hline Osirix & \multicolumn{1}{|c|}{$\checkmark$} & $\checkmark$ & (4D) only) \\
\hline
\end{tabular}

Table 3.comparison between some features of the software for the processing of blood flow

\section{MEDICAL ISSUE}

\section{A. Preamble}

In cooperation with the International Center Carthage Medical, we created our own database consisting of 200 cardiac sequences (Real Acquisition). The cuts presented in this section (Fig.2,Fig.3,Fig.4) are selected from this database to explain the steps of the diagnostic of cardiac examination. These sequences serve as like a tool to identify the problem and view the series of cardiac images. We used DICOM Viewer Tool version 9.0.2. DICOM (Digital Imaging Communications in Medicine) is considered among the most relevant solutions for the implementation used in radiology services. It provides a transparent access to metadata to provide a consolidated view of Data DICOM [42]. In fact, MRI cardiac is considered among the longest examinations (approximately 45 minutes). A detailed study can last longer. Provide 2 hours from reception to the delivery of the patient's images. In this section, it should be noted that we are only interested in the left part of the heart, which contains the mitral valve and the aortic one. Our study focuses on a typical case of a 10-year-old patient. His height is $160 \mathrm{~cm}$ and his weight is $55 \mathrm{~kg}$ with corporeal area of the aorta $1.6 \mathrm{~m}^{2}$. He was complaining from a severe stenosis at the aortic valve with a fraction of ejection $=82.5 \%$.

The acquisition protocol during a cardiac scans goes through 3 stages [1]: The first step is the acquisition of the main sequences shown in Fig.2 . The technical details of each images depicted in the tags of these images acquired with DICOM format (Digital Imaging and Communications in Medicine) are shown in table.4. The scan (2-a) shows the sequence of strict axial which has no interest in the analysis of the heart, although it is useful to start to visualize the anatomic appearance. The reconstruction of the sagittal plane or large axis cut is interesting to analyze the aortic root as seen in Fig.(2-b). The incidence of short axis is the most crucial cut in the cardiac examination since it is the only useful cut for the segmentation and the extraction of measures for diagnostic assistance as seen in Fig.(2-c). 


\begin{tabular}{|c|c|c|c|c|c|c|c|c|}
\hline Type of cardiac image & $\begin{array}{l}\text { FS } \\
\text { (Tesla) }\end{array}$ & $\begin{array}{l}\text { TR } \\
\text { (s) }\end{array}$ & TE(s) & $\begin{array}{l}\text { Th } \\
\text { (mm) }\end{array}$ & $\mathrm{HW}(\mathrm{mm}$ & $\begin{array}{l}\text { Ww } \\
(\mathrm{mm})\end{array}$ & Im & $\mathrm{Se}$ \\
\hline (a) Axial 3plane Loc Fiesta & 1.5 & 4.1 & 1.8 & 8 & 1818 & 3637 & $1 / 30$ & 1 \\
\hline (b) Large Axis Fiesta CINE & 1.5 & 3.7 & 1.6 & 8 & 1039 & 2078 & $1 / 20$ & 5 \\
\hline (c):short-axis Fiesta CINE & 1.5 & 3.7 & 1.6 & 8 & 711 & 1423 & $1 / 20$ & 7 \\
\hline (d) hunting chamber 4D Fiesta CINE & 1.5 & 3.8 & 1.7 & 8 & 795 & 1591 & $1 / 20$ & 10 \\
\hline
\end{tabular}

Table 4. details of the images during the scan:Field of strength in Tesla (FS);Time of Echo (TR);Time of Echo (TE);Thikness(Th);Height of window; window of window;Image (Im);Second(Se)

Fig.(2-d) presents the 4 cavities (hunting chamber) who has the role of checking the optimal prescription of the short axis plane used for the sake of the quantitative analysis. The Cut of hunting chamber has the role of identifying the altered valves and allows us to make a study of flux for this incidence shown in Fig.(2-e). It should be noted that it is not possible to obtain a sequence of cardiac flow from this cut.

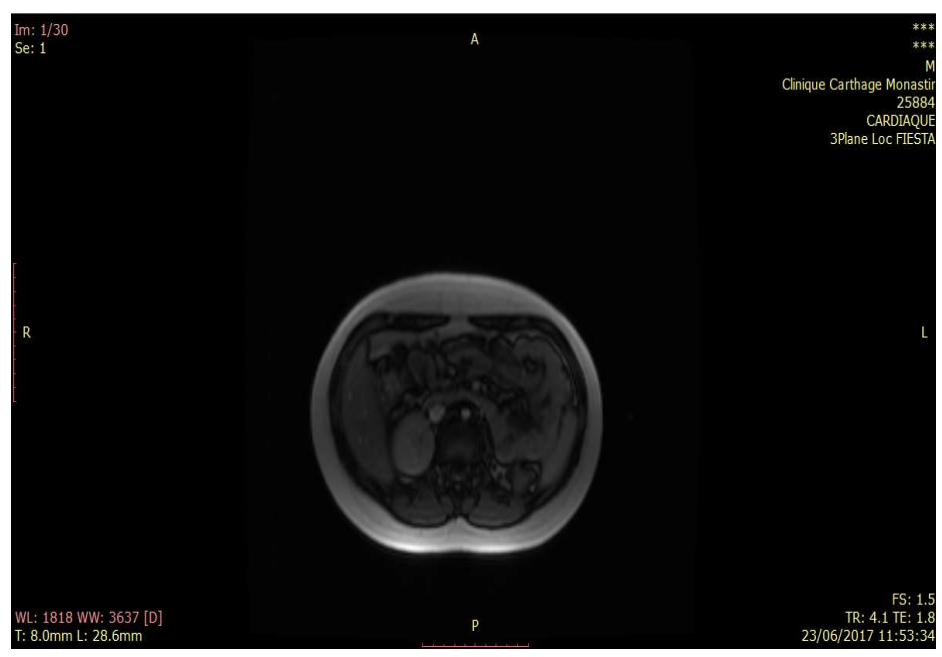

(a)

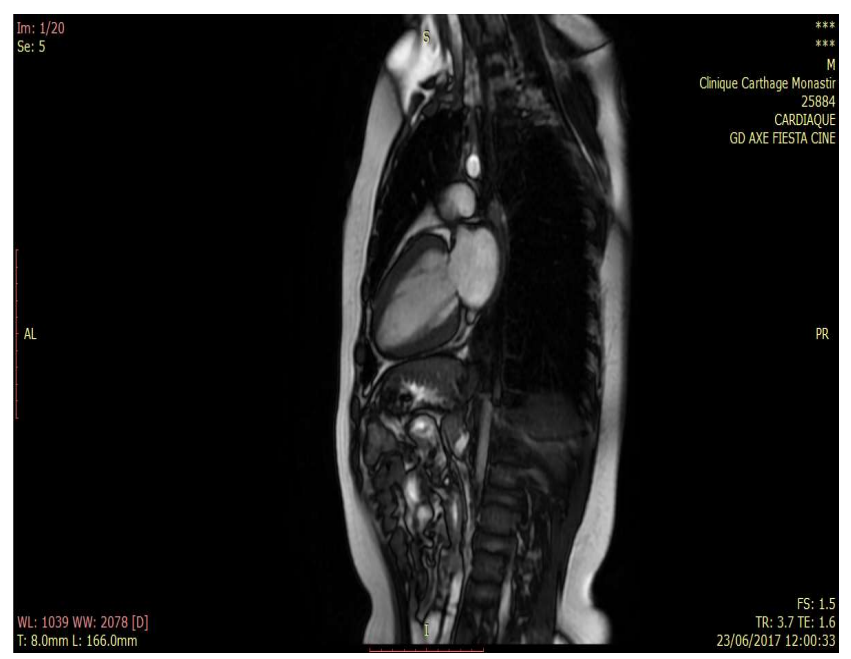

(b) 


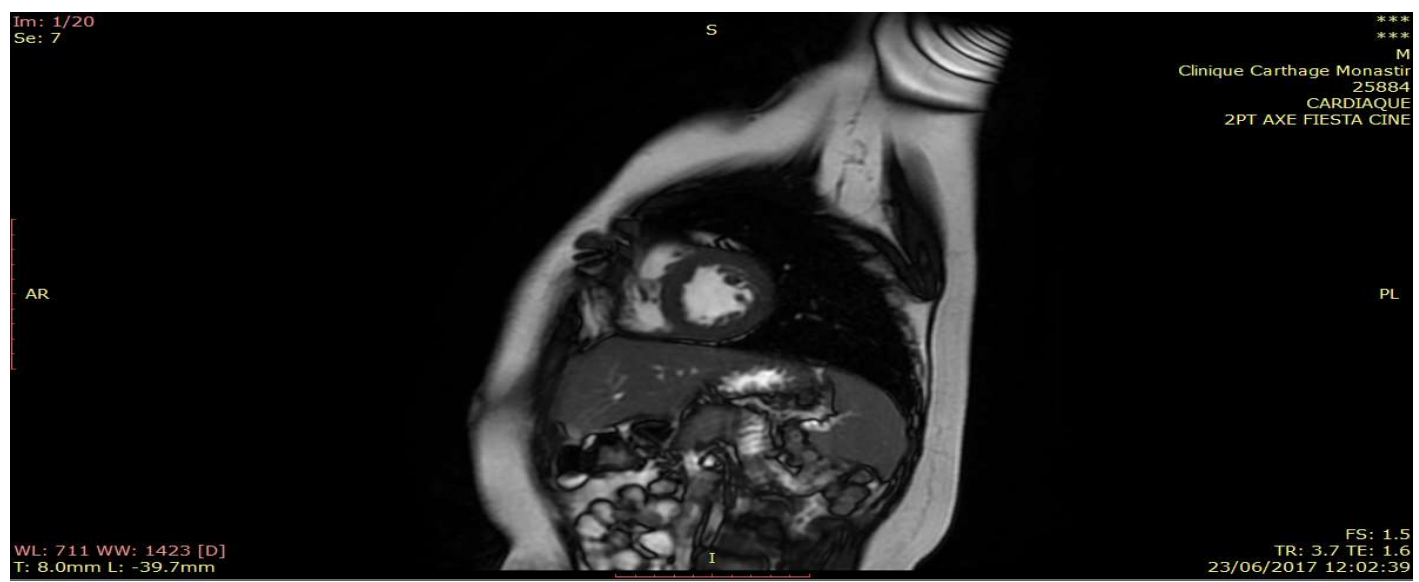

(c)

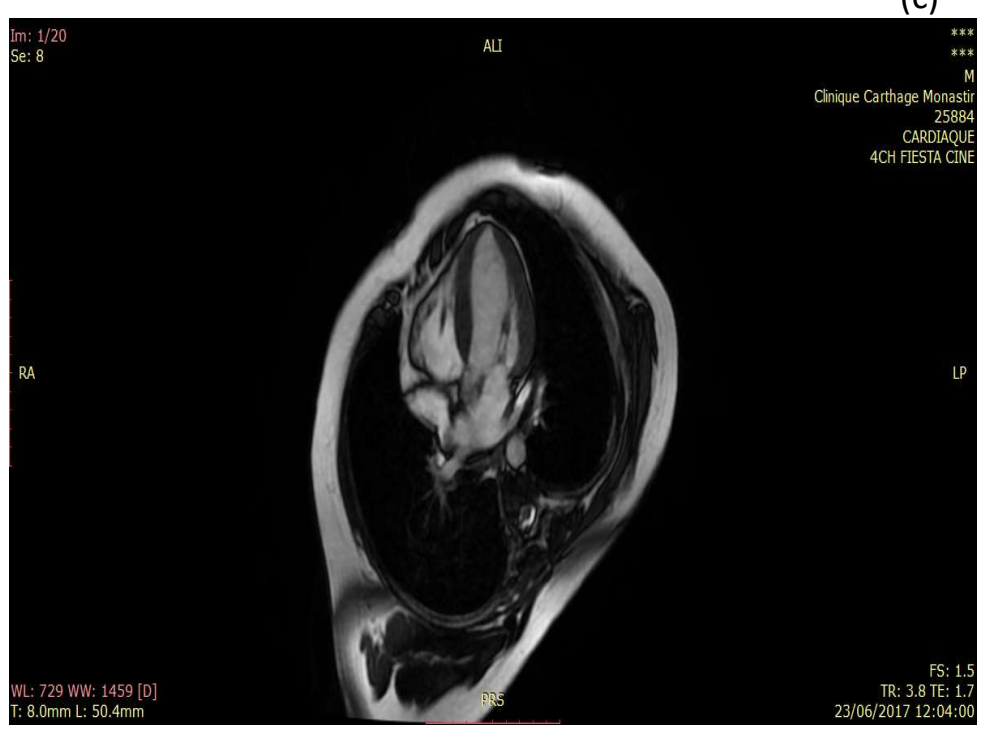

(d)

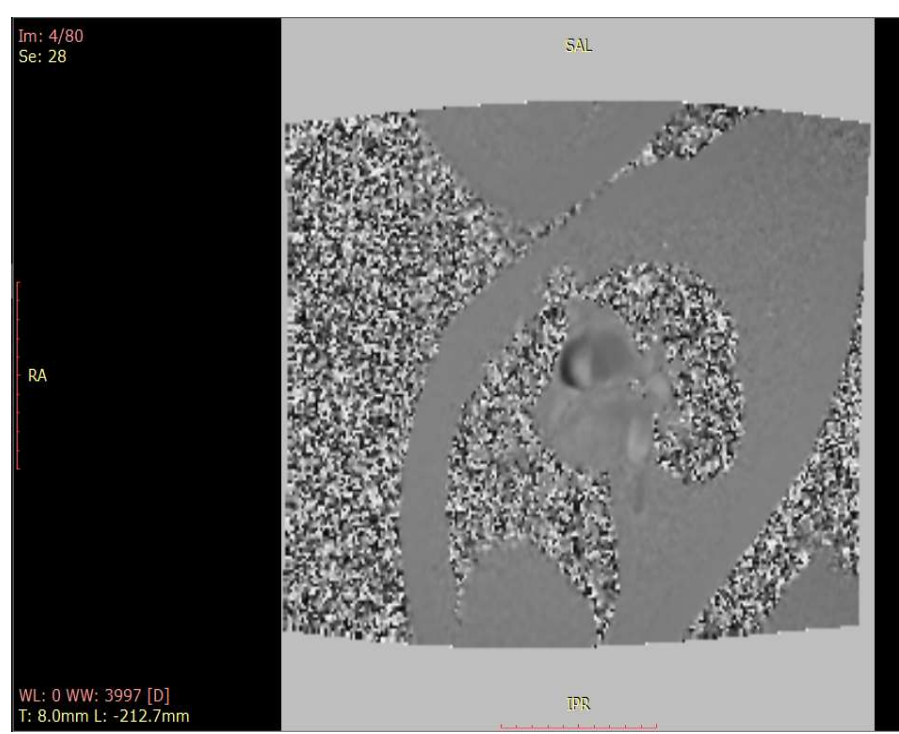

(e)

Figure 2.The main cuts of a cardiac examination during the acquisition :(a) strict axial ,(b) large axis, (c) short axis ,(d) 4 cavities (hunting chamber), (e) study of flux

The step of myocardial perfusion, which consist to the administration of gadolinium greatly enhances the myocardial signal, and reduces the contrast with the blood cavities. The injection is required during this process so that the radiologist can do a post-treatment. This step is interesting for the study of the viability of the vessels in order to detect that the patient have the symptoms of a cardiac infarction. The third step is the post-processing one: 


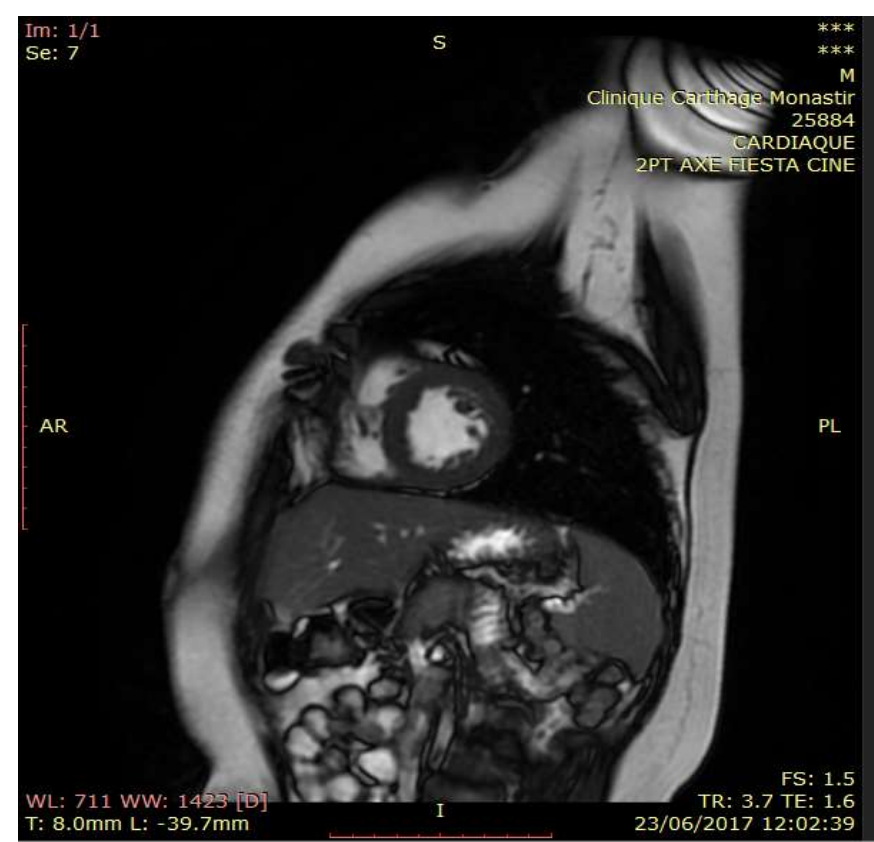

(a)

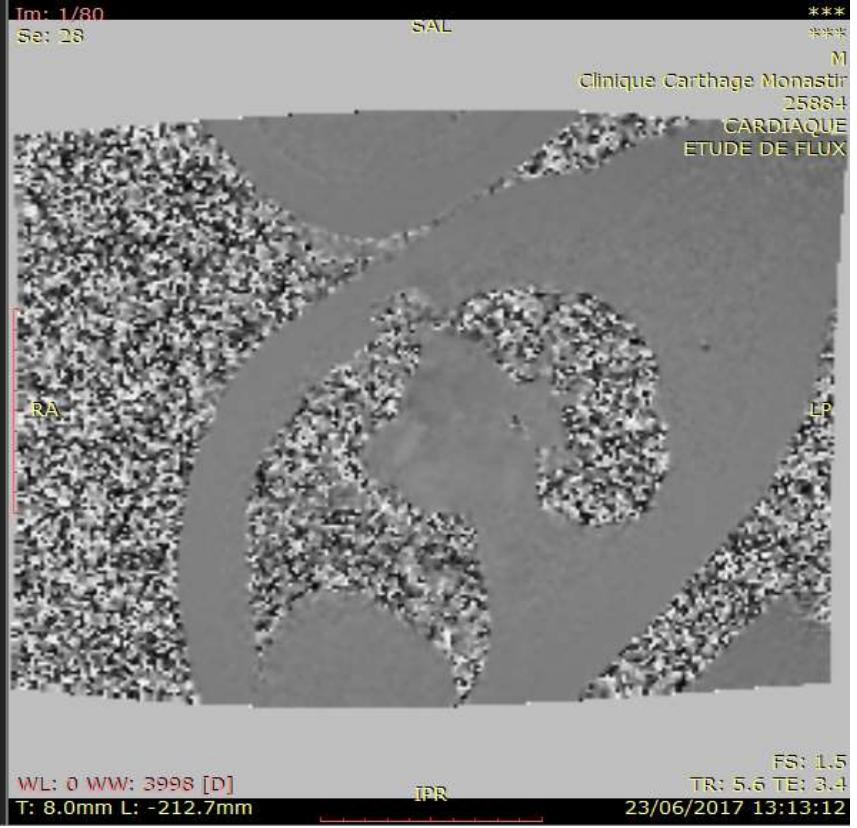

(b)

Figure 3.(a) 4D cardiac sequence of the same patient for 4 different instances, (b) Heart flow sequence

The post-processing step is to make the diagnosis of the expert by the 4D heart imaging interpretation through the cardiac cycle assessment over time and the calculation of cardiac parameters. In addition, it is the behavioral study of valves and quantification of the cardiac flow. This stage consists to visualize a 4D sequence and its study of flow so that the expert can make a correspondence between the two cuts in Fig.3.

B. Issue

The problem of segmentation in a short cut axis 4D and the matching with his study of blood flow revolves around three axes:

The 4D cardiac sequence is used only to calculate measurements and cardiac parameters such as the global fraction of systolic ejection, cardiac debit, diastolic and systolic volume and ventricular mass.

The problem arises when you cannot calculate directly and simultaneously these measures, we must necessary it go through the segmentation step in order to conduct a regional assessment of global ventricles and then regroup cuts (cardiac image reconstruction interest) to fraction of regurgitation from the measure of ventricular volumes, fraction of regurgitation from a measure of ventricular ejection volume, and calculation of blood flow quantification. This solution suffers from another source of error that is the misalignment between the plane and the direction of the cut flow. According to Olivier Vignaux [2] it was demonstrated that a misalignment of 20 degree produced a $6 \%$ error. A full diagnosis requires a long view time. The medical analysis of dynamic cardiac images is done in two separate parts: the analysis of 4D cardiac images and that of the flow sequence. 


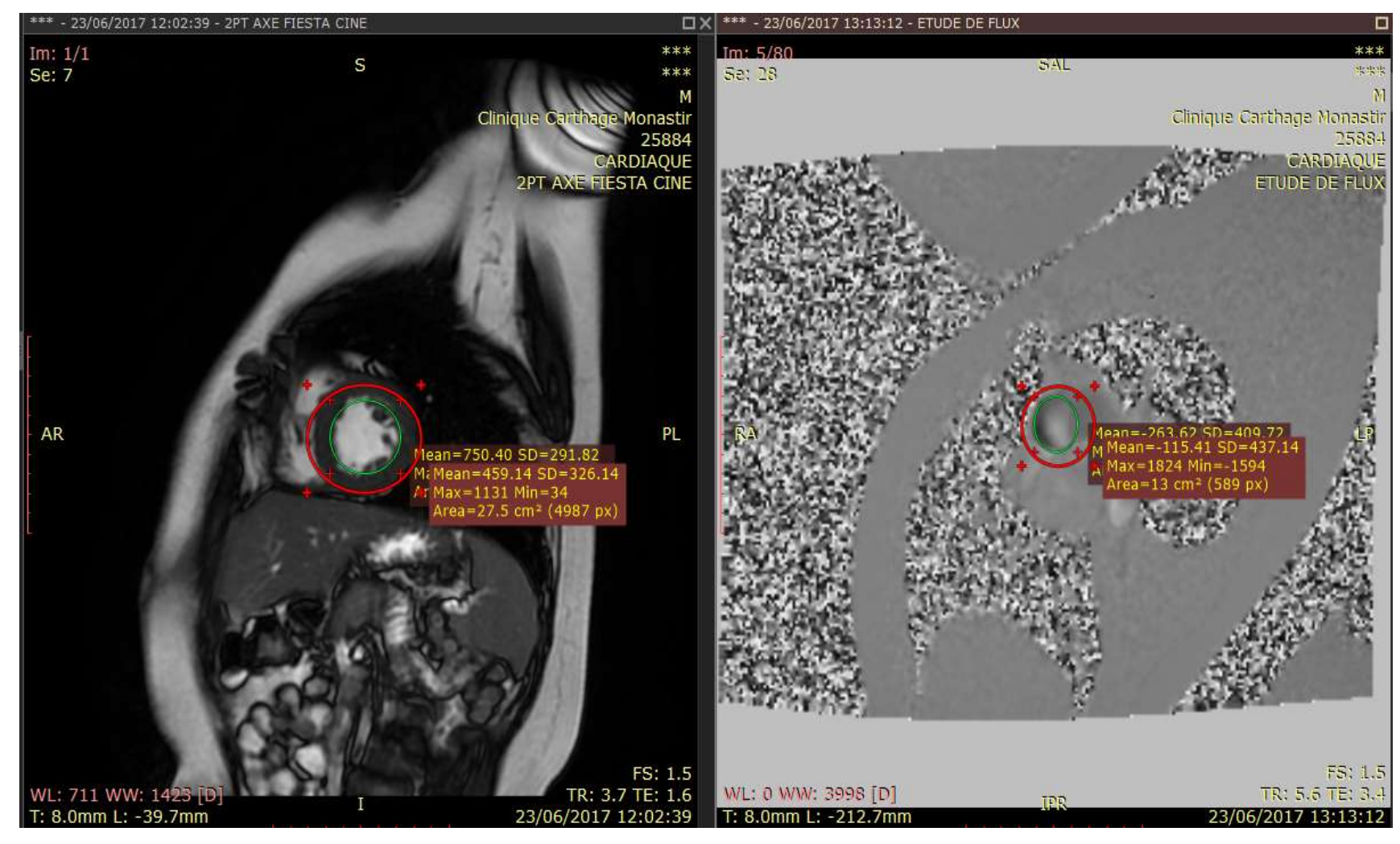

Figure 4.Steps of diagnosis

The medical diagnosis step consists of making the stage of the segmentation by the technique of contouring to extract both of the cardiac measurements from the short-axis 4D sequence and the valvulopathy parameters from the flow sequence is shown in Figure.4.

Following this step, the expert releases a set of measurement with the "ReportCard" tool maded by "GenaralElectric-Healtcare" which are summarized in Table.5.

\begin{tabular}{llllllll}
$\begin{array}{l}\text { Parameters } \\
\text { in the left }\end{array}$ & $\begin{array}{l}\text { diastolic } \\
\text { volume }\end{array}$ & $\begin{array}{l}\text { Systolic } \\
\text { volume }\end{array}$ & $\begin{array}{l}\text { Ejection } \\
\text { Volume }\end{array}$ & $\begin{array}{l}\text { Ejection } \\
\text { Fraction }\end{array}$ & $\begin{array}{l}\text { Flow } \\
\text { compensation }\end{array}$ & $\begin{array}{l}\text { Cardiac } \\
\text { Index }\left(\mathbf{l} / \mathbf{m i n} / \mathbf{m}^{2}\right)\end{array}$ & $\begin{array}{l}\text { maximum } \\
\text { velocity of }\end{array}$ \\
ventricular & $(\mathbf{m l})$ & $(\mathbf{m l})$ & $(\mathbf{m l})$ & $\mathbf{( \% )}$ & $(\mathbf{b m p})$ & & $\begin{array}{l}\text { ejection } \\
(\mathbf{m l} / \mathbf{m s e c})\end{array}$ \\
\hline Estimation & 43.6 & 7.6 & 35.9 & 82.5 & 82 & 1.9 & 0.4
\end{tabular}

Table 5.set of parameters extracted for the patient with aortic stenosis during the diagnostic phase with RepordCard

We provide also a blood volume simulation during 20 phase of time during the systole and diastole, which are depicted by the experts in Figure. 5 to evaluate the contractility function of the myocardium. 


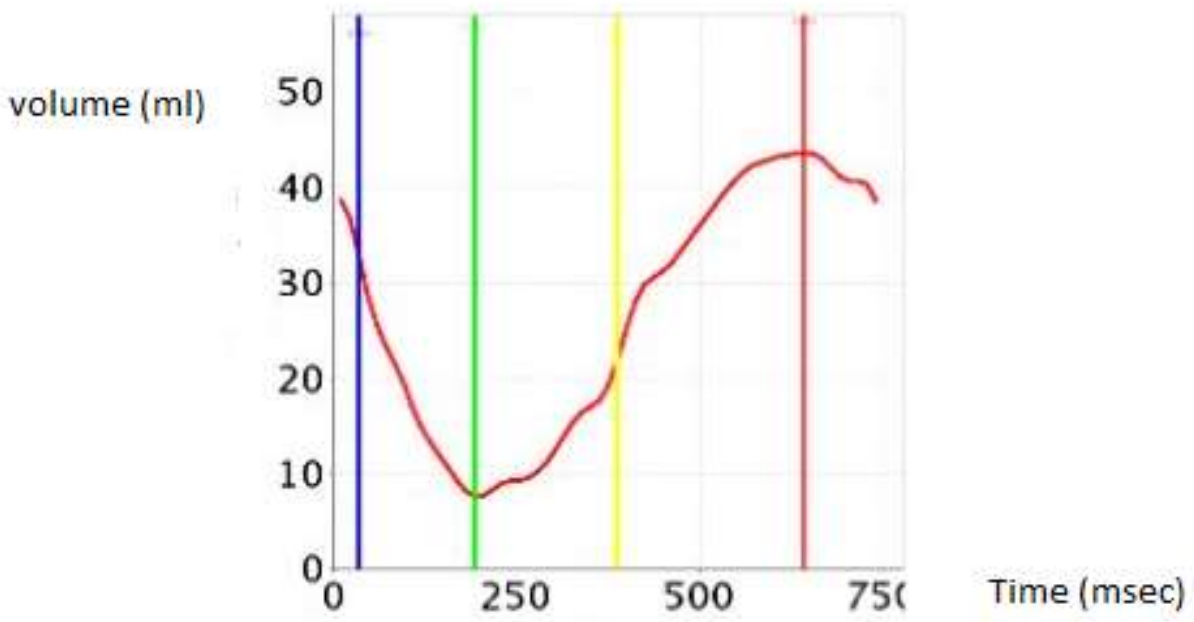

Figure 5.Volume curve with ReportCard

$\begin{array}{ccccc}\text { Measurement } & \text { Mean (pixels) } & \text { [Max-Min] (pixels) } & \text { Area } & \text { Standard Deviation } \\ \text { Short-axis } & 750,4 & {[91-1131]} & 11,64 \mathrm{~cm} 2 & 291,82 \\ \text { Study of flow } & -263,62 & {[-1244-464]} & 5,387 \mathrm{~cm} 2 & 409,91\end{array}$

Table 6.comparison of measurements of the segmentation area between the short-axis cut and the flow study

In this section, we repeat the step of the segmentation for the short-axis cut and the flow study we obtain a high error rate between the parameters presented in Table.6. Based on these results, we proposed a solution strategy based on 5D modeling that combines 4D sequences for short-axis and the flow study in a single sequence to avoid the error caused in this stage of segmentation, which may subsequently influence the medical decision. The main objective of this solution is to excite the velocity of the pixels based on the concept of flow imaging in the segmentation zone that lies between the epicardium and the endocardium. In order to obtain satisfactory results, we must rebuild sequences in 5D that highlights the flow around the area useful for segmentation then we will apply the registration approach to gather the heart structure in 4D.

We will focus on the estimation of the systolic ejection fraction which the crucial parameter for the detection of valvulopathies and the presence of cardiac abnormality.

\section{NEW APPROACH \& CONTRIBUTIONS}

\section{A. 5D concept: challenges and contribution}

The main objective of the $5 \mathrm{D}$ modeling is to add the flow dimension for $4 \mathrm{D}(3 \mathrm{D}+\mathrm{t})$ cardiac sequences to present a decision-making approach to the experts. The pathologies targeted by this approach are the case presented in the section (Preamble) and aortic leakage (regurgitation) in the left ventricle of the heart. Our contribution will be traduced via the excitation of pixel velocities (concept of flow imaging) in the segmentation area in short-axis sections in order to compute the average of the ejection fraction at the surface of each pixel. This method is considered as a promoter toward the experts in the estimation of the ejection fraction for the error that can be faced during the misalignment of segmentation of the myocardium. We Will to focus on the assertion of this parameter 
since it is considered the most important measure for the medical decision: if this fraction is between [55\%-70\%], the patient is considered as a healthy state, if he exceeds $75 \%$ the patient is possesses a genetic disease and if it is inferior to $50 \%$ the case complains of cardiac insufficiency (Stenosis or regurgitation). We presented a case of study for a patient with severe aortic stenosis in the previous section as well as a study for a patient aged 46, weight $=55 \mathrm{~kg}$, height $=160 \mathrm{~cm}$ with corporeal surface for the aorta $=1.5 \mathrm{~cm}^{2}$. The measurements taken in the prognosis phase are mentioned in table. 7 as well as the simulation of the volume curve during 20 phase of time indicted in Figure.6.

\begin{tabular}{|c|c|c|c|c|c|c|c|}
\hline $\begin{array}{l}\text { Parameters } \\
\text { in the left } \\
\text { ventricular }\end{array}$ & $\begin{array}{l}\text { diastolic } \\
\text { volume } \\
\text { (ml) }\end{array}$ & $\begin{array}{l}\text { Systolic } \\
\text { volume } \\
\text { (ml) }\end{array}$ & $\begin{array}{l}\text { Ejection } \\
\text { Volume } \\
(\mathrm{ml})\end{array}$ & $\begin{array}{l}\text { Ejection } \\
\text { Fraction } \\
(\%)\end{array}$ & $\begin{array}{l}\text { Flow } \\
\text { compensation } \\
\text { (bmp) }\end{array}$ & $\begin{array}{l}\text { Cardiac } \\
\operatorname{Index}\left(1 / \mathrm{min} / \mathbf{m}^{2}\right)\end{array}$ & $\begin{array}{l}\text { maximum } \\
\text { velocity of } \\
\text { ejection } \\
(\mathrm{ml} / \mathrm{msec})\end{array}$ \\
\hline Estimation & 179.9 & 142.7 & 37.2 & 20.7 & 62 & 1.5 & 0.5 \\
\hline
\end{tabular}

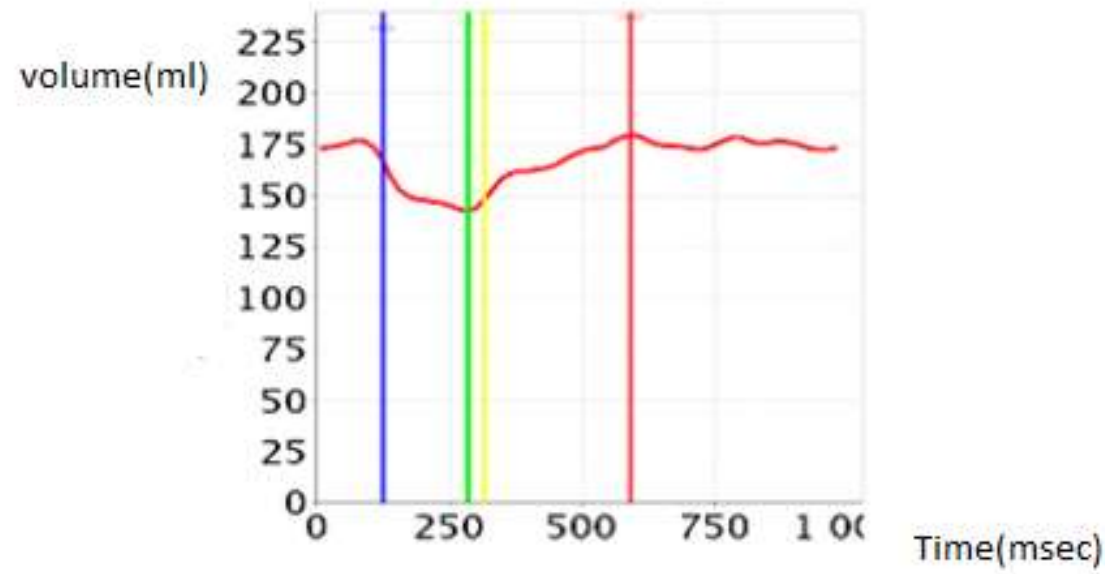

Figure 6. Volume curve for a patient with aortic leak with ReportCard

In fact, the work that highlights the concept of 5D in a straightforward way is limited until today. In the map of the location of our 5D, approach compared to this has already been treated; we list them in table 8 . 


\begin{tabular}{|c|c|c|c|}
\hline 5D Model by & Dimensions & Used approach & Condition of acquisition \\
\hline $\begin{array}{l}\text { Low et al.,2005 } \\
\text { [43] }\end{array}$ & $\begin{array}{l}\text { 3D current } \\
\text { volume of the } \\
\text { lungs }+t+ \\
\text { airflow } f(t)\end{array}$ & $\begin{array}{l}\text { Template } \\
\text { Matching }\end{array}$ & Irregular breathing cycles \\
\hline $\begin{array}{l}\text { Sigfridsson et al., } \\
2007 \text { [44] }\end{array}$ & $\begin{array}{l}\text { 3D heart volume } \\
+ \text { two temporal } \\
\text { dimensions, } \\
\text { similarly ( } t \text { heart }+ \\
t \text { l }_{\text {ungs }} \text { ) }\end{array}$ & Reconstruction & $\begin{array}{l}\text { Respiratory with cardiac } \\
\text { phase } \\
\text { arbitrary }\end{array}$ \\
\hline $\begin{array}{l}\text { Feng et al.,2017 } \\
\text { [45] }\end{array}$ & $\begin{array}{l}\text { 4D heart volume } \\
+ \text { Respiratory } \\
\text { dimension }\end{array}$ & Reconstruction & $\begin{array}{l}\text { Arbitrary respiratory and } \\
\text { cardiac phase }\end{array}$ \\
\hline Proposed Model & $\begin{array}{l}\text { 3D heart volume } \\
+t+\text { blood flow }\end{array}$ & $\begin{array}{l}\text { Reconstruction } \\
\text { and rigid } \\
\text { registration }\end{array}$ & In apnea \\
\hline
\end{tabular}

Table 8: classification of research work for the 5D concept

By observing this work, we find that two 5D models combine the cardiac system with the pulmonary system based on temporal dimensions. In fact, our medical context revolves around a decision-making approach for a purely cardiac concept. For this reason, we make an analogy with the 5D modeling for the lungs but with other techniques and different condition of acquisition since this methodology has shown its inefficiency for the detection of nodules without the intervention of the cardiac cycle.

We have analyzed the cardiac concept $5 \mathrm{D}$ while taking as a starting point the model by the lungs $5 \mathrm{D}$ to evaluate the effectiveness of template Matching which consist primarily to make a superposition between the cuts of hunting-chamber and their study of flow. Resulted show that the detected common points it is the orifice of the aortic valve as well as an assessment of the maximum velocity. These measurements were not sufficient to supplement the diagnosis. A simulation of flow was carried out in order to deduce from the indices of escape or occlusion for the forecast by basing its behavior. Unfortunally, this approach were not satisfactory with regard to the expert

Following these results, we have moved towards the technique of reconstruction, which stipulates to eliminate the morphologic structure in 3D from the sequences short-axis and to keep only the edge of the zone of the segmentation. In second place, we have exit a cloud of the pixels around the myocardial while basing ourselves on their contrast of gray. After obtaining the cuts of shorts axis in 2D, we used the approach of rigid registration with a fifth level of pyramid to superpose the old incidences 3D with that in 2D. The interpretation of this preliminary results were promoter for the estimate of the fraction of ejection for both of cases (aortic and regurgitation case) 
Our solution is based to make a coupling between a 4D cardiac sequence and a flow sequence for a dynamic cardiac 5D image format. We denoted by C4DF the Coupling a 4D Flow. We propose to adopt the registration and the reconstruction technique to obtain a 5D cardiac sequence. The flow coupling 4D consists of performing a registration in order to merge a $4 \mathrm{D}$ image with a flow sequence and the reconstruction for the correction of the mafic zones following the registration. The need to accelerate the acquisition and increase the spatial resolution of cardiac MRI images has led to the proposal of several reconstruction methods. These methods use a priori information (acquired data) to find those missing[46]. The advantage of this registration is to combine functional images and sharp anatomical images made by MRI cardiac [47]. The principal objective of segmentation is cutting an image related regions, with homogeneity, according to a certain criterion, such as color. The union of these regions must restore the original image[48]. We can distinguish in this case two types of segmentation: an approach of contouring which is, in fact, a clinical solution which leads to a loss of morphological information[2]. On the other side, the watershed approach has been renewed for morphological MRI cardiac imaging. Therefore, we would keep the morphological information (valve leaflets, valvular thickening ...) during the diagnostic strategy in valvular to ensure a reliable diagnosis [49].

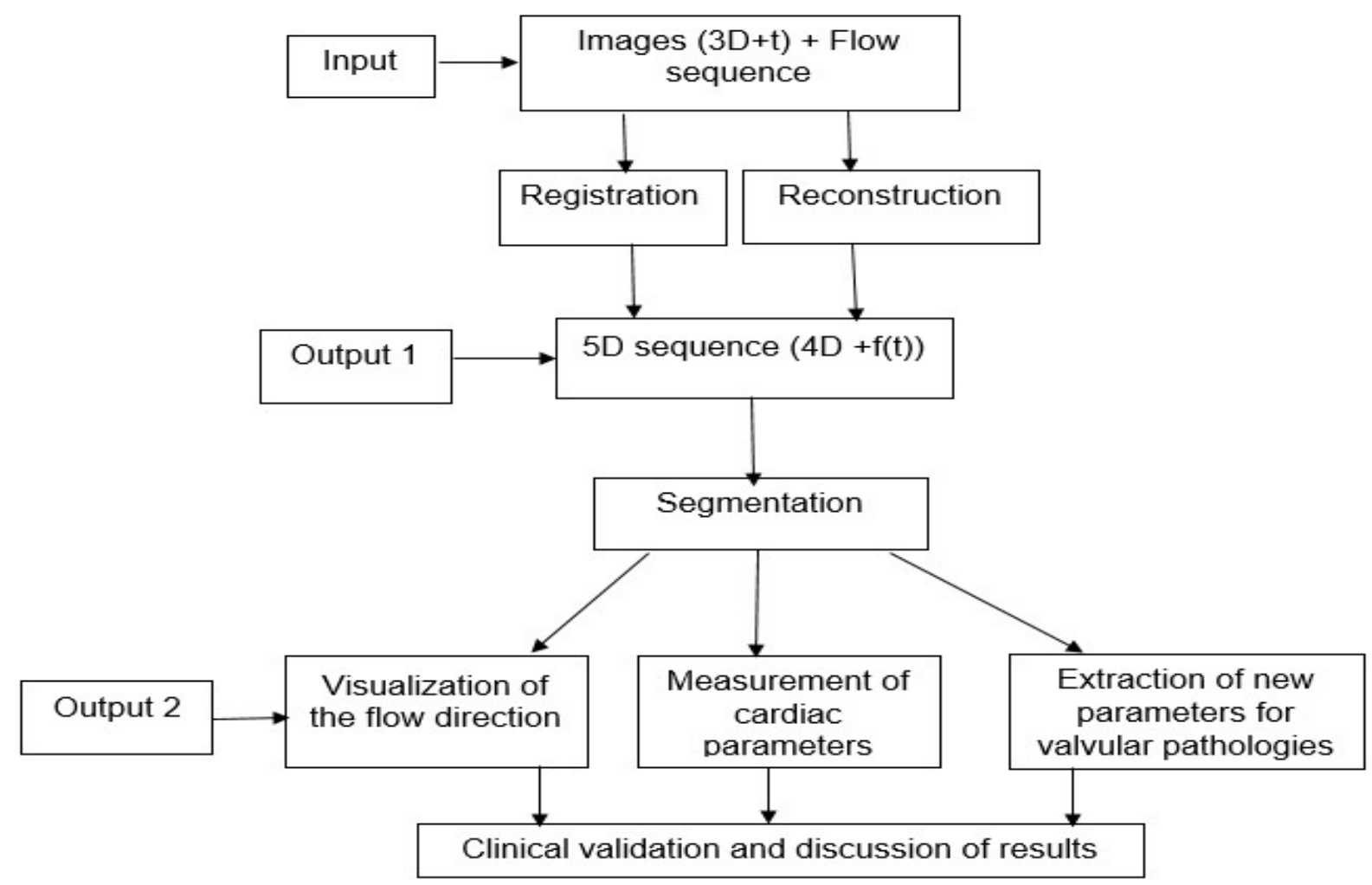

Figure 7.Proposition of processing chain to get a 5D sequence

This processing chain shown in Fig.7 summarizes the procedure that will be followed to solve the problem of correspondence between a 4D cardiac sequence and its study of flow. To validate the segmentation step it was necessary to have a 5D sequence, which retains the same morphological characteristic and the cardiac tissue structure and the blood flow, can be visualized in the same 5D cardiac image. The reliability of this solution depends on the quality of the recalculated parameters (global fraction of systolic ejection, diastolic and systolic 
volume, cardiac debit, Ventricular mass...) and the measures that can be extracted (volume of the ejected flow, volume of the regurgitated flow, regurgitation fraction (ejected flow / regurgitated flow), ejection volume (ejected flow - regurgitated flow) from the database of selected patients which have valvulopathies disease In particular, these measures exist in the medical literature but are not found in the clinical routine. This solution aims to propose a decision-making approach for the experts to detect heart and valvular diseases to improve the accuracy of the ejection fraction in the first degree, then, the extraction of the new measurements for the severity of severity assessment in the event of valvular or aortic occlusion or regurgitation based in CFD modules.

\section{B. Challenges and goals}

The goals referred to as the Coupled 4D Flow (C4DF) solution are summarized in Figure.8:

(a)

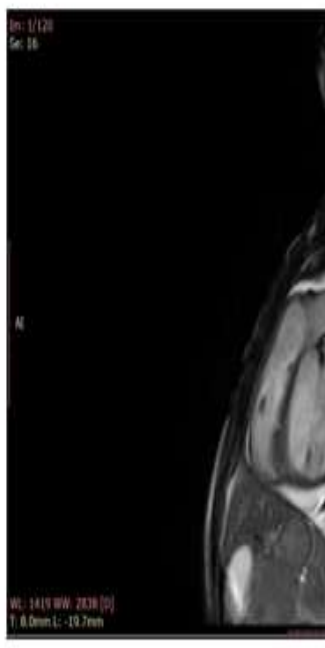

(b)

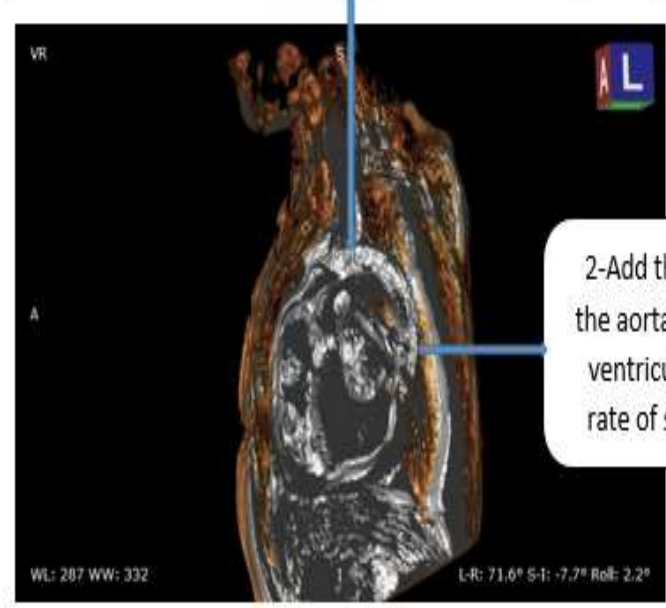

Goals

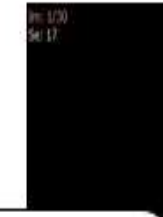

1-Add the blood flow (fifth dimension) into the aorta in the $4 D(3 D+t=175)$ short Axis cut to assess the fraction of ejection in in myocardial muscle
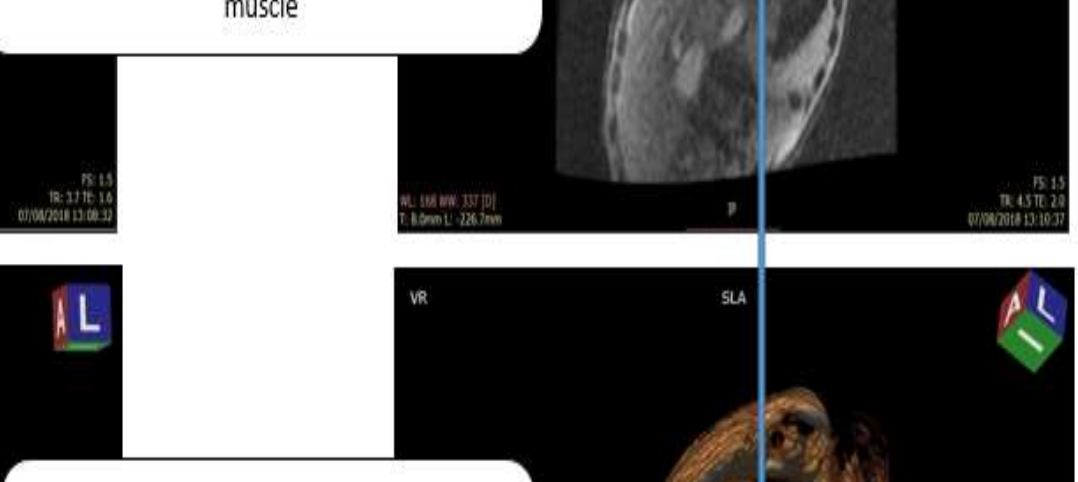

(d)

Figure 8.Patient with aortic regurgitation :(a)RVOT (right ventricular outflow tract) cut $4 D$,(b) Reconstruction 3D of RVOT Cut ,(c)Short axis 4D cut ,(d) Reconstruction 3D of the short-axis cut

The challenges identified after the 5D design are detailed as follows:

- Eliciting cardiac Morphology and tissue characterization that will be clear and reliable as a source of medical interpretation.

- Calculating the cardiopahty and valvulopathy parameters (fraction of systolic ejection, fraction of regurgitation ...) that are released from a single cardiac sequence flow in a 5D format.

- Improving the measures of information mentioned above [34]. 
- Reducing the rate of errors caused by the segmentation process (Unnecessary surgical intervention).

- Assisting in the planning of the procedure and determining the size of the valve prosthesis to be implanted in case of severe a stenosis.

- Improving the accuracy of the size of the valvuloplasty in function of the regurgitation orifice in case of valvular insufficiency

- Predicting any operative risk

- Improve the qualitative aspects (assessment of segmental contractility and global segmentation) and quantitative (cardiac quantification of flow blood)

- Gaining in terms of diagnosis time

\section{COMPARAISON BETEWEEN THE LUNG AND CARDIAC MODEL5D}

A mathematical model 5D was developed for the lungs that depends on 5 dimensions which are :[43]

- The parameters of the object (anatomical structure)

- The volume of flow at a time $t$

- The flow of air $f$ corresponding $(t)$ at this same time

To validate the hypothesis $5 \mathrm{D}$, we must develop a linear model. This simulates the movement of a 3D object by separating the information on the volume flow $v(t)$ and on the flow air; $f(t)$. It defines the position of a point to the $r_{\rho} \rho$ stage following the given expression [2].

$$
\overrightarrow{\mathrm{r}}_{\mathrm{p}}=\alpha \mathrm{v} \widehat{\mathrm{r}}_{v}+\beta \mathrm{f} \widehat{\mathrm{r}}_{\mathrm{f}}
$$

- The linear model is based on the parameters and constants described $\overrightarrow{r_{v}}$ and $\overrightarrow{r_{\mathrm{f}}}$ the constants $\alpha$ and $\beta$

$\overrightarrow{r_{v}}=\alpha v \vec{r}_{v}:$ direction of movement of the current volume lungs

$\overrightarrow{\mathrm{r}_{\mathrm{f}}}=6 \mathrm{v} \overrightarrow{\mathrm{r}}_{\mathrm{f}}:$ variation of air flow rate

The quantities $\alpha$ and $\beta, \overrightarrow{\mathrm{r}_{\mathrm{v}}}$ and $\overrightarrow{\mathrm{r}_{\mathrm{f}}}$, are the function of the initial phase $(\overrightarrow{\mathrm{r} 00})$

They vary according to the respiratory cycle (filling and emptying of air)

The quantities $\alpha$ and $\beta, \overrightarrow{\mathrm{r}_{\mathrm{v}}}$ and $\overrightarrow{\mathrm{r}_{\mathrm{f}}}$ are calculated from real-time patient images

The 5D lung model is based on the Template Matching solution. This solution treats the volume of the lungs with the time parameter (4D sequence) with an independent and separated way from the airflow. The proposed model does not account for tumor motion due to the cardiac cycle. As the time required to acquire the $\mathrm{CT}$ scans decreases (the minimal time with the new $\mathrm{CT}$ scanner is currently $0.3 \mathrm{~s}$ ), tumor motion owing to the cardiac cycle may be imaged in the scans. If the cardiac cycle is measured along with the breathing cycle, it may be possible to add cardiac motion to the model. If the cardiac cycle is measured throughout a respiratory movement, it may be possible to add a cardiac movement to the model .Also, the motion model can map lung function using the trajectories measured for an air flow and the flow movement data determined from the different phases provide additional information on lung function. 
The Interpolation of this model parameters will be possible and the behavior of the model could be used to determine the local air fill and drain by the control of the divergence of local airflow movement of the lungs. We propose to extend the characteristics of the [Low] model for a cardiac flow model by integrating the cardiac cycle. The objective is to associate the current volume of the heart with the cardiac blood flow by applying the technique of registration and reconstruction to improve the accuracy of the results of cardiac blood flow rate and extract new parameters for valvulopathies since the study of flow is intended for the diagnosis of valvular abnormalities and some congenital cardiopathies.

\section{HYBRID MULTICORE APPLIED TO DYNAMIC FLUID}

Fluid dynamics problems are classified into the categories of problems of big data because of the use of partial differential equations (PDEs) of high degree. The equation of elastic waves is widely used in the fields of fluid dynamics. We mention for example the equation of Navier -Stokes of 4th order which is often used to solve the problem of elastic fluids [50].The parallelization of the GPU has been successfully applied to the propagation of elastic waves, see [51],[52]. Generally, problems involving partial differential equations (PDE) perform a very heavy calculation with a high degree of accuracy, which subsequently enhances the response time. Several research papers propose to use the hybrid CPU architecture Computer Processing Unit) and GPU (Graphics Processing Unit) to speed up the calculation. In this case, the optimization must be started from a lower level. Once the code is fully optimized for a single CPU node, we can upgrade to multiple CPUs, CPU / GPU cluster optimization. Multi-core processors are commonly used that support API (Application Programming Interface), such as OpenMP and POSIX Threads, and SIMD (Single Instruction Multiple Data) commands. The SSE (Streaming SIMD Extensions) and AVX (Advanced Vector Extensions) extensions use these SIMD instructions[53]. In this section, we are interested in citing the works that exploit the multicore CPU-GPU architecture in the domain application of dynamic and elastic fluids as our medical context is based on blood fluid. The proposal of an adequate architecture Is used to improve the calculation time of the cardiac parameters to be extracted through the use of CPU, as well as optimizing the complexity of the algorithms of the data processing by the GPU paralleling aspect. We list some works to evaluate the interest of the CPU-GPU architecture in our medical context for the study of blood flow and 4D cardiac images. Although CPU and GPU processors are often used to solve such problems, the parallelization of any calculation starts from an Optimization for image processing algorithms. Graphics processors invade the majority of processing units in the medical field. These GPUs, designed to accelerate graphics applications (rendering 3D, 4D images), have a large number of computing units, providing much more computing power than CPUs. This power has aroused the interest of many researchers to exploit the GPUs in order to carry out other types of processing carried out on CPU. Therefore, the objective of this study is to explore the use of a rapidly updated dynamic movement pattern to correct motions induced respiratory errors guided by MRI cardiac procedures. The motivation for the proposed technique is to improve the MRI guidance accuracy by exploiting the anatomical aspect of earlier high-resolution images in a series of real-time MRI images [54]. The increasing size of the 4D data sets by magnetic resonance imaging (MRI) requires effective cardiac segmentation algorithms. A deep study in [55] recall that the segmentation phases are generated in a multithreaded CPU in 10 seconds or less. The simplicity of algorithms of the results of calculation causes a loss of precision. A more complex graphics 
processing unit (GPU) of the basic algorithm adjusts the data flow of the Gaussian waveforms, and produces a first segmentation of 0.5 seconds. Level sets are then applied to an amplitude image, where the initial conditions are given by the previous algorithms CPU and GPU. A comparison of results shows that the GPU algorithm seems to produce a more precise segmentation. Graphics processing units (GPUs) are used in a wide range of medical imagery, mainly because they can significantly accelerate parallel computing, and they are affordable and energy efficient [56]. In this context, the reconstruction problem by MRI was made with some samples of the acquired body with this modality [57]. Missing information in the Fourier domain causes image artifacts. They proposed a regularization approach based on the second order derivative of both simulated and real images with highly subsampled data, in order to obtain a good accuracy of the reconstruction. In addition, an accelerated regularization algorithm, using a projection technique combined with an implementation on Graphics Processing Unit (GPU) is presented. A novel algorithm was proposed in [58] based on the lattice Boltzmann method (LBM) using graphics processing units (GPU) to accelerate this method. Nevertheless, in this method, the time is not suitable for the GPU based computations. To complete this survey, we need a GPU graphics processor for processing images acquired by MRI, and a CPU to perform complex arithmetic operations applied to the image processing algorithms. Our focus on the acceleration of these methods is mainly due to the increase in the intensity calculation of such applications. The utility of a powerful CPU is translated through the calculation of cardiac parameters and parameters of valvular disease. The growth speed of processing units (CPU) improves the acquisition sequences but the graphics data processing (GPU) guarantee that the reconstruction of cardiac images in the post-processing phase is treated instantaneously [13]. We propose the use of efficient, and hybrid architectures (GPU / GPU) to improve the performance of the methods of treatment of the objects used in image processing algorithms and medical applications as well as in analysis and monitoring in real time movements.

\section{CONCLUSION}

In this paper, we focus on the issues faced by the expert in the cardiology domain. Among these problems is the extraction of accurate parameters of heart disease from the 4D cardiac sequence and the segmentation step in its study of the blood flow via the hunting chamber cut. The insufficiency of several parameters of valvulopathies, the difficulty of the interpretation of these measures makes the study of flow embarrassing for radiologists. Based on the two extreme cases mentioned in this paper that present a severe case of aortic stenosis with an ejection fraction $=82.5 \%$ and a case of aortic leakage with an ejection fraction $=20.7 \%$, we found a lack of specific measurements for the study of flow in order to quantify the rate of stenosis or leakage and locate it in a specific way.

In this context, we proposed a processing chain towards a $5 \mathrm{D}$ solution for this issue by proposing a coupling between a $4 \mathrm{D}$ cardiac sequence and a flow sequence in the objective of obtaining a dynamic cardiac 5D image, instead of the solution based in the Template Matching proposed by Low. Our solution consists to apply the technique of registration in order to merge a $4 \mathrm{D}$ image with a flow sequence and the reconstruction technique for the correction of the mafic zones following the registration.

We proposed also to exploit hybrid (GPU / GPU) architectures in order to improve the performance of object processing methods used in image processing algorithms and medical applications as well as analysis and real- 
time tracking. Our interest in the acceleration of these methods is mainly due to the increase in the intense calculation of the MRI applications. Our contributions concern a proposition of a decision-making approach via a cardiac model 5D, which integrates a functional dimension of the blood, flow.

\section{ACKNOWLEDGEMENT}

International Medical Carthage Center supported this work. Special thanks to the medical staff for providing us with as access to the archive of patients and the administrative framework for the warm welcome in their team.

\section{REFERENCES}

[1] "Site officiel de l'Organisation mondiale de la Santé." [Online]. Available: http://www.who.int/fr. [Accessed: 27-Sep-2018].

[2] O. Vignaux, Imagerie cardiaque : scanner et IRM, Second Edition. ELSEVIER MASSON, 2011.

[3] H. Watanabe et al., "Estimation of intraoperative blood flow during liver RF ablation using a finite element method-based biomechanical simulation," in 2011 Annual International Conference of the IEEE Engineering in Medicine and Biology Society, 2011, pp. 7441-7445.

[4] A. Swillens, P. Segers, H. Torp, and L. Lovstakken, "Two-dimensional blood velocity estimation with ultrasound: speckle tracking versus crossed-beam vector doppler based on flow simulations in a carotid bifurcation model," IEEE Trans. Ultrason. Ferroelectr. Freq. Control, vol. 57, no. 2, pp. 327-339, Feb. 2010.

[5] H. Kadowaki, T. Hayase, K. Funamoto, and N. Taniguchi, "Study of Estimation Method for Unsteady Inflow Velocity in Two-Dimensional Ultrasonic-Measurement-Integrated Blood Flow Simulation," IEEE Trans. Biomed. Eng., vol. 63, no. 2, pp. 403-414, Feb. 2016.

[6] R. Laurent, "Simulation du mouvement pulmonaire personnalisé par réseau de neurones artificiels pour la radiothérapie externe - document," University of ranche-Comt e, 2013.

[7] V. M. Ferreira, M. D. Robson, T. D. Karamitsos, M. M. Bissell, D. J. Tyler, and S. Neubauer, "6 Magnetic resonance imaging," in Advanced Cardiac Imaging, K. Nieman, O. Gaemperli, P. Lancellotti, and S. Plein, Eds. Woodhead Publishing, 2015, pp. 127-169.

[8] N. S. Burris and M. D. Hope, "4D Flow MRI Applications for Aortic Disease," Magn. Reson. Imaging Clin. N. Am., vol. 23, no. 1, pp. 15-23, Feb. 2015.

[9] J. Mikhail Kellawan et al., "Quantitative cerebrovascular 4D flow MRI at rest and during hypercapnia challenge," Magn. Reson. Imaging, vol. 34, no. 4, pp. 422-428, May 2016.

[10] E. J. Keller, J. D. Collins, C. Rigsby, J. C. Carr, M. Markl, and S. Schnell, "Superior Abdominal 4D Flow MRI Data Consistency with Adjusted Preprocessing Workflow and Noncontrast Acquisitions," Acad. Radiol., vol. 24, no. 3, pp. 350-358, Mar. 2017.

[11] T. H. Oechtering et al., "Time-resolved 3-dimensional magnetic resonance phase contrast imaging (4D Flow MRI) analysis of hemodynamics in valve-sparing aortic root repair with an anatomically shaped sinus prosthesis," J. Thorac. Cardiovasc. Surg., vol. 152, no. 2, pp. 418427.e1, Aug. 2016.

[12] G. B. Kim et al., "Post-stenotic plug-like jet with a vortex ring demonstrated by 4D flow MRI," Magn. Reson. Imaging, vol. 34, no. 4, pp. 371-375, May 2016.

[13] M. Cibis et al., "The effect of resolution on viscous dissipation measured with 4D flow MRI in patients with Fontan circulation: Evaluation using computational fluid dynamics," J. Biomech., vol. 48, no. 12, pp. 2984-2989, Sep. 2015.

[14] F. von Knobelsdorff-Brenkenhoff, R. F. Trauzeddel, A. J. Barker, H. Gruettner, M. Markl, and J. Schulz-Menger, "Blood flow characteristics in the ascending aorta after aortic valve replacement-a pilot study using 4D-flow MRI," Int. J. Cardiol., vol. 170, no. 3, pp. 426-433, Jan. 2014. 
[15] J. Garcia et al., "Evaluation of aortic stenosis severity using 4D flow jet shear layer detection for the measurement of valve effective orifice area," Magn. Reson. Imaging, vol. 32, no. 7, pp. 891898, Sep. 2014.

[16] F. Scardulla et al., "Shear stress alterations in the celiac trunk of patients with a continuous-flow left ventricular assist device as shown by in-silico and in-vitro flow analyses," J. Heart Lung Transplant., vol. 36, no. 8, pp. 906-913, Aug. 2017.

[17] N. S. J. Elliott, A. D. Lucey, D. A. Lockerby, and A. R. Brodbelt, "Fluid-structure interactions in a cylindrical layered wave guide with application in the spinal column to syringomyelia," J. Fluids Struct., vol. 70, pp. 464-499, Apr. 2017.

[18] B. Thomas and K. S. Sumam, "Blood Flow in Human Arterial System-A Review," Procedia Technol., vol. 24, pp. 339-346, Jan. 2016.

[19] M. Roy, B. Singh Sikarwar, M. Bhandwal, and P. Ranjan, "Modelling of Blood Flow in Stenosed Arteries," Procedia Comput. Sci., vol. 115, pp. 821-830, Jan. 2017.

[20] K. W. Lee and X. Y. Xu, "Modelling of flow and wall behaviour in a mildly stenosed tube," Med. Eng. Phys., vol. 24, no. 9, pp. 575-586, Nov. 2002.

[21] C. W.Y, "Simulation of arterial stenosis incorporating fluid-structural interaction and nonNewtonian blood flow," RMIT University, Australia, 2006.

[22] F. Ghalichi, X. Deng, A. De Champlain, Y. Douville, M. King, and R. Guidoin, "Low Reynolds number turbulence modeling of blood flow in arterial stenoses," Biorheology, vol. 35, no. 4-5, pp. 281294, Oct. 1998.

[23] D. Bluestein, C. Gutierrez, M. Londono, and R. T. Schoephoerster, "Vortex shedding in steady flow through a model of an arterial stenosis and its relevance to mural platelet deposition," Ann. Biomed. Eng., vol. 27, no. 6, pp. 763-773, Dec. 1999.

[24] M. Cibis et al., "Relation between wall shear stress and carotid artery wall thickening MRI versus CFD," J. Biomech., vol. 49, no. 5, pp. 735-741, Mar. 2016.

[25] Y. Hoi, Y.-Q. Zhou, X. Zhang, R. M. Henkelman, and D. A. Steinman, "Correlation between local hemodynamics and lesion distribution in a novel aortic regurgitation murine model of atherosclerosis," Ann. Biomed. Eng., vol. 39, no. 5, pp. 1414-1422, May 2011.

[26] M. M. G. H. J. Helwegen, L. E. Young, K. Rogers, and J. L. N. Wood, "Measurements of right ventricular internal dimensions and their relationships to severity of tricuspid valve regurgitation in national hunt thoroughbreds," Equine Vet. J. Suppl., no. 36, pp. 171-177, Aug. 2006.

[27] A. S. Anayiotos, P. Fan, G. J. Perry, J. Myers, A. M. Elmahdi, and N. C. Nanda, "Analysis of the Proximal Orifice Flowfield Under Pulsatile Flow Conditions and Confining Wall Geometry: Implications in Valvular Regurgitation," Echocardiogr. Mt. Kisco N, vol. 15, no. 3, pp. 219-232, Apr. 1998.

[28] K. Vellguth et al., "Development of a modeling pipeline for the prediction of hemodynamic outcome after virtual mitral valve repair using image-based CFD," Int. J. Comput. Assist. Radiol. Surg., Jul. 2018.

[29] S. Ho, G. X. Y. Tan, T. J. Foo, N. Phan-Thien, and C. H. Yap, "Organ Dynamics and Fluid Dynamics of the HH25 Chick Embryonic Cardiac Ventricle as Revealed by a Novel 4D High-Frequency Ultrasound Imaging Technique and Computational Flow Simulations," Ann. Biomed. Eng., vol. 45, no. 10, pp. 2309-2323, Oct. 2017.

[30] M. C. Stevens, F. M. Callaghan, P. Forrest, P. G. Bannon, and S. M. Grieve, "Flow mixing during peripheral veno-arterial extra corporeal membrane oxygenation - A simulation study," J. Biomech., vol. 55, pp. 64-70, Apr. 2017.

[31] P. Clarysse, "Analyse d'images cardiaques assistée par les modèles," Habilitation, University of Science and Technology, Lille, 2007.

[32] J. Bogaert, S. Dymarkowski, A. M. Taylor, and V. Muthurangu, Clinical Cardiac MRI, Second Edition. Springer, 2012.

[33] "QFlow post-processing software." [Online]. Available: https://www.medis.nl/Products/QFlow. [Accessed: 27-Sep-2018]. 
[34] "Pie Medical Imaging - Solutions in cardiovascular analysis," Pie Medical Imaging. [Online]. Available: https://www.piemedicalimaging.com/. [Accessed: 27-Sep-2018].

[35] "Purview | OsiriX eXperts - Fanatical support for OsiriX." .

[36] A. Kačeniauskas, R. Pacevič, V. Starikovičius, A. Maknickas, M. Staškūnienè, and G. Davidavičius, "Development of cloud services for patient-specific simulations of blood flows through aortic valves," Adv. Eng. Softw., vol. 103, pp. 57-64, Jan. 2017.

[37] L. Goubergrits et al., "Is MRI-based CFD able to improve clinical treatment of coarctations of aorta?," Ann. Biomed. Eng., vol. 43, no. 1, pp. 168-176, Jan. 2015.

[38] K. Jain, J. Jiang, C. Strother, and K.-A. Mardal, "Transitional hemodynamics in intracranial aneurysms - Comparative velocity investigations with high resolution lattice Boltzmann simulations, normal resolution ANSYS simulations, and MR imaging," Med. Phys., vol. 43, no. 11, p. 6186, Nov. 2016.

[39] C. Karmonik, C. Yen, O. Diaz, R. Klucznik, R. G. Grossman, and G. Benndorf, "Temporal variations of wall shear stress parameters in intracranial aneurysms--importance of patient-specific inflow waveforms for CFD calculations," Acta Neurochir. (Wien), vol. 152, no. 8, pp. 1391-1398; discussion 1398, Aug. 2010.

[40] J. Bruening et al., "Impact of patient-specific LVOT inflow profiles on aortic valve prosthesis and ascending aorta hemodynamics," J. Comput. Sci., vol. 24, pp. 91-100, Jan. 2018.

[41] A. Amindari, L. Saltik, K. Kirkkopru, M. Yacoub, and H. C. Yalcin, "Assessment of calcified aortic valve leaflet deformations and blood flow dynamics using fluid-structure interaction modeling," Inform. Med. Unlocked, vol. 9, pp. 191-199, Jan. 2017.

[42] M. Santos, L. Bastião, N. Neves, D. Francisco, A. Silva, and N. P. Rocha, "DICOM Metadata Access, Consolidation and Usage in Radiology Department Performance Analysis. A Non-proprietary Approach," Procedia Comput. Sci., vol. 64, pp. 651-658, Jan. 2015.

[43] D. A. Low et al., "Novel breathing motion model for radiotherapy," Int. J. Radiat. Oncol., vol. 63, no. 3, pp. 921-929, Nov. 2005.

[44] A. Sigfridsson, J.-P. E. Kvitting, H. Knutsson, and L. Wigström, "Five-dimensional MRI incorporating simultaneous resolution of cardiac and respiratory phases for volumetric imaging," J. Magn. Reson. Imaging JMRI, vol. 25, no. 1, pp. 113-121, Jan. 2007.

[45] L. Feng et al., "5D whole-heart sparse MRI," Magn. Reson. Med., May 2017.

[46] J. Adrienne and Y. NJIWA, "Reconstruction d'images de résonance magnétique à partir de l'espace k partiel," The National Institute of Applied Sciences, Lyon, 2007.

[47] N. Betrouni, "Le recalage en imagerie médicale : de la conception à la validation," IRBM, vol. 30, no. 2, pp. 60-71, Apr. 2009.

[48] J. Cousty, L. Najman, M. Couprie, S. Clément-Guinaudeau, T. Goissen, and J. Garot, "Segmentation of 4D cardiac MRI: Automated method based on spatio-temporal watershed cuts," Image Vis. Comput., vol. 28, no. 8, pp. 1229-1243, Aug. 2010.

[49] L. Najman, "Morphologie mathématique, systèmes dynamiques et applications au traitement des images," Habilitation, Université de Marne-la-Vallée, ESIEE Paris, 2006.

[50] H.-H. Chang and C.-Y. Tsai, "Adaptive registration of magnetic resonance images based on a viscous fluid model," Comput. Methods Programs Biomed., vol. 117, no. 2, pp. 80-91, Nov. 2014.

[51] D. Michéa and D. Komatitsch, "Accelerating a three-dimensional finite-difference wave propagation code using GPU graphics cards," Geophys. J. Int., vol. 182, no. 1, pp. 389-402, 2010.

[52] F. Rubio, M. Hanzich, A. Farrés, la P. de, and C. María, "Finite-difference staggered grids in GPUs for anisotropic elastic wave propagation simulation," Comput. Geosci., vol. 70, pp. 181-189, 2014.

[53] S. Titarenko and M. Hildyard, "Hybrid multicore/vectorisation technique applied to the elastic wave equation on a staggered grid," Comput. Phys. Commun., vol. 216, pp. 53-62, Jul. 2017.

[54] R. Xu and G. A. Wright, "GPU accelerated dynamic respiratory motion model correction for MRIguided cardiac interventions," Comput. Methods Programs Biomed., vol. 136, pp. 31-43, Nov. 2016. 
[55] R. V. Bergen, H.-Y. Lin, M. E. Alexander, and C. P. Bidinosti, "4D MR phase and magnitude segmentations with GPU parallel computing," Magn. Reson. Imaging, vol. 33, no. 1, pp. 134-145, Jan. 2015.

[56] A. Eklund, P. Dufort, D. Forsberg, and S. M. LaConte, "Medical image processing on the GPU Past, present and future," Med. Image Anal., vol. 17, no. 8, pp. 1073-1094, Dec. 2013.

[57] F. Piccialli, S. Cuomo, and P. De Michele, "A Regularized MRI Image Reconstruction based on Hessian Penalty Term on CPU/GPU Systems," Procedia Comput. Sci., vol. 18, pp. 2643-2646, Jan. 2013.

[58] S. Balla-Arabé, X. Gao, D. Ginhac, and F. Yang, "Shape-constrained level set segmentation for hybrid CPU-GPU computers," Neurocomputing, vol. 177, pp. 40-48, Feb. 2016. 